\title{
Benefiting from Injustice and the Common-Source Problem
}

\author{
Göran Duus-Otterström ${ }^{1,2,3}$ (D)
}

Accepted: 27 October 2017 / Published online: 7 November 2017

(C) The Author(s) 2017. This article is an open access publication

\begin{abstract}
According to the Beneficiary Pays Principle, innocent beneficiaries of an injustice stand in a special moral relationship with the victims of the same injustice. Critics have argued that it is normatively irrelevant that a beneficiary and a victim are connected in virtue of the same unjust 'source'. The aim of this paper is to defend the Beneficiary Pays Principle against this criticism. Locating the principle against the backdrop of corrective justice, it argues that the principle is correct in saying that innocent beneficiaries of an injustice may have an extra reason to assist the victims of that injustice. This is because it may be necessary to defeat the immoral plan of the perpetrator of the injustice and because it may satisfy weak restitution. The conclusion is that the principle is distinctive from related views, such as that property should be returned to its rightful owner or that tainted benefits should be given up for general use.
\end{abstract}

Keywords Beneficiary pays principle $\cdot$ Compensation $\cdot$ Corrective justice $\cdot$ Injustice $\cdot$ Restitution

\section{Introduction}

Many philosophers and political theorists today accept

The Beneficiary Pays Principle (BPP): 'the involuntary receipt of benefits stemming from injustice can, in some circumstances, give rise to rectificatory obligations to the victims of the injustice in question' (Butt 2014, p. 336).

Göran Duus-Otterström

goran.duus-otterstrom@pol.gu.se

1 Department of Political Science, University of Gothenburg, Box 711, 40530 Gothenburg, Sweden

2 Department of Political Science, Aarhus University, Aarhus, Denmark

3 Institute for Futures Studies, Stockholm, Sweden 
This principle has been invoked in a wide range of debates. ${ }^{1}$ It is often originally attributed to J.J. Thomson (1973), who drew on it in her defense of preferential hiring. Today it is perhaps most widely discussed in the literature on how the burdens of mitigating and adapting to climate change should be allocated, where BPP is sometimes considered a valuable complement to the Polluter Pays Principle. ${ }^{2}$ The merit of the principle, according to its defenders, is that it allows us to assign remedial obligations even when the perpetrators of an injustice cannot or will not accept liability, but without relying on brute ability to pay.

BPP needs to be fleshed out in several ways. One question concerns the proper definition of benefits. This has partly to do with settling the metric of benefits, that is, whether 'benefits' refer to welfare, resources, or something else. But it also involves working out the generic meaning of what it means to benefit from something. Victor Tadros (2014) refers to this as the measure of benefits. The traditional (counterfactual) understanding is that an actor $A$ 'benefits' from $X$ if and only if $X$ renders $A$ better off than $A$ would otherwise have been. But it could also be argued that $A$ 'benefits' from $X$ simply if $X$ produced some good that ended up in $A$ 's possession. On this actual-sequence approach to benefiting, it is not necessary that $X$ render $A$ better off than otherwise (Lippert-Rasmussen 2017, p. 85). ${ }^{3}$

Another question concerns how to understand the 'injustice' from which actors benefit. This is not always straightforward. Consider, for example, the case of climate change: should we target (1) the benefits flowing from excessive greenhouse gas emissions, (2) the benefits flowing from the international failure to prevent climate change, or (3) the benefits flowing from the changing climate? The choice makes a big difference for which actors BPP will single out. The benefits that were produced by past emissions, for example, are probably not the same as the benefits produced by the international policy failure.

But suppose we have completed these steps, and suppose further that we agree that benefits stemming from injustice at least sometimes should be disgorged, even when people have done nothing wrong to possess them. ${ }^{4}$ This would not amount to our accepting BPP, because it does not commit us to the 'directed' nature of this principle. Note that Daniel Butt's formulation talks specifically about rectificatory obligations to 'the victims of the injustice in question'. This feature is common to almost all formulations of BPP. The idea is that there is normative significance to the fact that someone gains and someone else loses as the result of the same injustice, such that the person who gains has rectificatory obligations to the person who loses in particular. In the climate justice debate, for example, it is often claimed that a large share of the costs of responding to climate change should be covered specifically by wealth stemming from the economic activities that caused climate change (Shue 1999; Page 2012; DuusOtterström 2014). This directedness is what makes BPP different from a view like undirected disgorgement, according to which tainted benefits should be given up but go back into society's general pool of resources (Goodin 2013). Let us say that BPP posits that there is normative significance to the fact that there is a 'common source'-typically a wrongfully

\footnotetext{
${ }^{1}$ See, e.g., Anwander (2005); Butt (2007, 2009, 2014); Pogge (2008); Barry and Kirby (2017). BPP is sometimes referred to as 'the benefiting view' or the 'wrongful benefit principle'.

${ }^{2}$ For BPP and climate justice, see, e.g., Shue (1999); Gosseries (2004); Caney (2005); Page (2012); LawfordSmith (2014).

${ }^{3}$ Lippert-Rasmussen (2017, pp. 81-86) makes further illuminating distinctions relating to how the baseline of comparison is set.

${ }^{4}$ For cases where the beneficiaries are not morally innocent, see Pasternak (2014) and Goodin and Pasternak (2016).
} 
harmful act or policy — between victims and beneficiaries. This means that the principle is, as I shall also say, 'source sensitive'.

Source sensitivity with respect to benefiting from injustice may seem intuitively plausible, but advocates of BPP regularly omit to explain why it is important, and several critics have recently argued that it is in fact normatively irrelevant. ${ }^{5}$ Worse, they maintain that it leads BPP into making mistaken recommendations (Knight 2013; Huseby 2015; Parr 2016; LippertRasmussen 2017). ${ }^{6}$ These two claims are intertwined. The charge is that BPP results in various kinds of unfairness because it mistakenly assumes that common sources matter. To see what the critics have in mind, consider the case Carl Knight (2013, p. 587) calls Unfortunate.

Unfortunate. In her dying moment, Wrongdoer unjustly harms Victim and, as a result of this, Beneficiary innocently benefits. When Victim is harmed, she becomes as badly off as Unfortunate, who suffers from some natural event. ${ }^{7}$

Since BPP holds that it is normatively significant that harms and benefits flow from the same unjust source - in this case Wrongdoer's harmful act - it entails that Beneficiary has a reason to address Victim's loss that she does not have towards Unfortunate. The critics argue that this is wrongheaded. Victim and Unfortunate are equally badly off for reasons beyond their control. To favor Victim would therefore be unfair to Unfortunate. If Beneficiary were unable to assist both Victim and Beneficiary, it would be fairer if she split her illicit benefit between the two, or, if the benefit is indivisible, decided whom to help by flipping a coin. The fact that Beneficiary and Victim are causally connected in virtue of Wrongdoer's act is a 'quite superficial reason' to favor Victim (Huseby 2015, p. 219; cf. Knight 2013, pp. 594-595; Parr 2016, pp. 989-991; Lippert-Rasmussen 2017, pp. 78-79).

In response, it could be stressed that BPP is not intended as a comprehensive approach to distributing duties. If nothing else, this is evident from the fact that most would hold Wrongdoer under the primary duty to remedy Victim's loss if she were still around. Since BPP is only one part of a bigger, pluralist picture, it could easily work alongside other principles that mandate that Unfortunate should be helped, for example, a principle saying that there is a general duty to protect others from harm. But this response, while correct, misses the challenge laid down by the critics. They want to know why we should assign Beneficiary a special duty to assist Victim in the first place.

Another response is that there is nothing strange about claiming that Victim should have priority over Unfortunate, because, other things being equal, it is worse to be a victim of wrongdoing than it is to suffer from bad brute luck. But this response does not rescue BPP, because even if victims of wrongdoing can press stronger claims on assistance than the unlucky, it can just as well be asked why innocent beneficiaries should prioritize the victims with whom they are source connected over other victims. Consider:

Victims. In her dying moment, Wrongdoer 1 unjustly harms Victim 1 and, as a result of this, Beneficiary innocently benefits. Wrongdoer 2 also acts in her dying moment, and as

\footnotetext{
${ }^{5}$ For examples where BPP's source sensitivity is endorsed but not explained, see Page (2012, p. 307); Goodin (2013, p. 489); Lawford-Smith (2014, p. 396); Barry and Kirby (2017, p. 295).

${ }^{6}$ While these critics share this worry about BPP, it is important to point out that they have different aims. Knight (2013) argues that luck egalitarianism is strictly preferable to BPP. Huseby (2015) only makes the negative point that BPP is indefensible. Lippert-Rasmussen's (2017) main aim is likewise to reject BPP, but he also argues that luck egalitarianism can explain what seems right about BPP. Parr (2016), finally, seeks to reject what he calls the 'Connection Account' in favor of the 'Moral Taintedness Account'. We will return to Parr's position in section 2.

${ }^{7}$ I have taken some liberties with Knight's case.
} 
a result of this Victim 2 is unjustly harmed. Wrongdoer 1 and Wrongdoer 2 acted independently of each other. Victim 1 and Victim 2 are unjustly harmed to the same extent.

Here BPP holds that Beneficiary has a special reason to assist Victim 1 that she does not have to assist Victim 2. This is what differentiates BPP from the position known as the Generalized BPP, according to which beneficiaries of injustice in general have rectificatory obligations towards victims of injustice in general (Huseby 2015, p. 221). And, again, the challenge is to explain why this sort of source sensitivity is justifiable. If neither Victim 1 nor Victim 2 could help what happened, and they are harmed to the same extent, then why prioritize Victim 1 as opposed to flipping a coin between them?

Let us refer to this challenge as the common-source problem. The problem can be stated as follows:

Common-source problem. Is there any normative significance to a common source between unjust harms and unjust benefits such that those who innocently draw benefits from an injustice have special moral reason to remedy the situation of those who are unjustly harmed by that injustice, that is, a moral reason to address this harm in particular?

Notice that this formulation refers to 'reasons' as opposed to 'duties'. While the debate about BPP is often couched in the language of duties or obligations, it is enough here to consider whether common sources can alter the moral reasons of innocent beneficiaries in the sense of making it more morally important or appropriate that they assist the victims with whom they are source connected. The meaning of 'altered moral reasons' should be clarified, though, because we can mean two different things by this: that innocent beneficiaries are picked out to redress the victims, or that innocent beneficiaries have a reason to prioritize the victims over other people. I shall use the latter sense. A useful way of bringing out what I have in mind is the following: suppose you have benefitted from an injustice and are to give this benefit up. Does the fact that some were victimized by the same injustice give you a special moral reason to direct the benefit to those people? Supplying an affirmative answer is the same thing as solving the common-source problem.

It is important to underline that we are only looking for a special reason for beneficiaries to prioritize the victims, not a reason that is supposed to knock out all other moral considerations. Some critics have argued that BPP is absurd since it instructs beneficiaries to attend to the victims with whom they are source connected even though others are in much greater need of assistance. For example, in Unfortunate, BPP instructs Beneficiary to remedy Victim's loss even though Unfortunate might be in much worse shape (Knight 2013, p. 596). This would indeed be absurd, but a proponent of BPP need not say that Beneficiary has a conclusive reason to direct her disgorged benefit to Victim. As we just noted, it is crucial to distinguish between what Beneficiary should do all-things-considered and what she should do as far as $\mathrm{BPP}$ is concerned. It is perfectly coherent to hold that BPP gives Beneficiary a reason to assist Victim but that this reason is outweighed by the reasons to assist Unfortunate instead. We are here only interested in whether there is any reason to believe, as BPP says, that Beneficiary has an extra reason to assist Victim simply because they are connected in virtue of the same unjust action. This is compatible with holding that this reason is quite weak all-things-considered (for example, that it can only break ties between otherwise identically situated recipients of assistance). 


\section{Defeating Unjust Plans}

We are trying to explain, then, why innocent beneficiaries of an injustice have a special moral reason to prioritize the victims of the same injustice. But just not any explanation will do. First, while the explanation might show that innocent beneficiaries have reason to prioritize the victims only in some cases of innocent benefiting, it must provide a non-accidental basis for source sensitivity. ${ }^{8}$ Second, the explanation must flow from the normative ideal behind BPP, which is corrective justice.

I will argue that there are two explanations satisfying these criteria. First, as explained in this section, source sensitivity may follow from the idea of defeating the plan the perpetrator of an injustice might have had in terms of the allocation of benefits and harms. Second, as explained in section 3, source sensitivity might follow from what I will call weak restitution. Before I go on to develop these explanations, however, it is important to first say a few words about what it means to say that BPP is a principle of corrective justice.

Corrective justice is the species of justice concerned with 'rectification of the wrongful invasions of legitimate entitlements that people hold' (Ivison 2006, p. 511). Unlike distributive justice, which focuses on the pattern of allocation of goods, corrective justice thus focuses on wrongful acts, and on the steps needed to rectify those acts (Duus-Otterström 2017). ${ }^{9}$ In slogan form, it is about 'righting wrongs' ${ }^{10}$

It is widely held that BPP is a principle of corrective justice (Butt 2014; Huseby 2015; Lippert-Rasmussen 2017). ${ }^{11}$ This means that when the principle states that innocent beneficiaries of unjust acts have special reasons or obligations towards the victims of those acts, this is not because it would be more distributively just if the beneficiaries compensated the victims. Rather, it is because such compensation is called for by the aim of righting wrongs. When the perpetrator of an injustice for some reason cannot be held liable, so the argument goes, beneficiaries of the injustice may incur a reason or obligation to undo the effects of the injustice as this would go at least some way towards righting the wrong done to the victims.

Whether BPP is distinct from principles of distributive justice admittedly depends on the relationship between corrective and distributive justice. Cohen (2016) usefully distinguishes between the subordination thesis and the autonomy thesis. The subordination thesis holds that corrective justice is entirely derivative of the pattern provided by distributive justice. Remedies under 'corrective justice are justifiable only as devices to bring about some distributive

\footnotetext{
${ }^{8}$ An accidental basis for source sensitivity might be the following: suppose $A$ is under a duty not to benefit from injustice only on Mondays. If $A$ innocently benefits from an injustice on a Monday, she would then have a special reason to prioritize the victim with whom she is source connected, but this would not be true if she benefited on any other day of the week. This would be far too flimsy to solve the common-source problem. However, I agree with Haydar and Øverland (2014) that it is needlessly strong to demand that every innocent beneficiary always have a special reason to remedy the victims of the injustice. Haydar and Øverland argue that BPP is only activated given that certain further conditions (they call them 'boosting' factors) are satisfied. The accounts I offer in sections 2 and 3 are examples of such conditions.

${ }^{9}$ There is a discussion as to whether BPP should only work with unjust acts or if it could also incorporate unjust events (Huseby 2015, p. 210). Since BPP is a principle of corrective justice, there is good reason to reserve it for acts (Lippert-Rasmussen 2017, pp. 79-80).

10 'Righting wrongs' can mean different things. See the framework in Goodin (2013), distinguishing between compensation, punishment, restitution, punishment, and disgorgement.

${ }^{11} \mathrm{BPP}$ is sometimes advanced as a principle for the allocation of remedial responsibility, which strictly speaking is not about (or does not have to be about) corrective justice. For remedial responsibility, see Miller (2001).
} 
improvement' (Cohen 2016, p. 664). ${ }^{12}$ The autonomy thesis denies this. It holds that corrective justice can operate independently of the pattern provided by distributive justice. To illustrate the difference, suppose someone steals from you. Should the belongings be returned as a matter of corrective justice? According to the subordination thesis, to answer this question we must investigate whether returning your belongings would improve the way goods are distributed. The belongings should not be returned unless it would take us closer to a distributively just pattern (say, of resources). According to the autonomy thesis, on the other hand, we only need to consider whether you had a legitimate entitlement not to have your belongings stolen in this way. If you did, corrective justice requires that the belongings be returned even though it would not represent a distributive improvement.

It is important to note, however, that even if we find the subordination thesis too strong, we are not forced to say that corrective justice is entirely freestanding from distributive justice. This would only follow if we were dealing with invasions of entitlements whose legitimacy in no way is informed by distributive justice. For example, it could be argued that theft is a wrongful invasion that should be rectified no matter how unjust the distribution of material resources. But it could also be argued the background distribution must be just or reasonably just before rectification is called for as a matter of justice (Perry 2000). This might mean that no rectification is called for when the unjustly poor steal from the unjustly rich. ${ }^{13}$ None of what I say depends on settling this issue, but the examples I discuss do assume that a wrongful invasion has occurred. The reader should fill in the distributive background conditions he or she deems necessary to elicit this intuition.

Let us now return to the common-source problem, keeping in mind that we are looking for reasons for source sensitivity that are recognizably about righting wrongs. To get things started, consider the following scenario:

Thefts. Ada steals $\$ 100$ from Bob and gives it to wholly innocent Clare as a gift. Meanwhile, David, who is totally unrelated to the whole situation, has also been robbed of $\$ 100$. Clare, Bob, and David have fully adequate lives and are similarly well off.

Let us assume that Ada's theft was a wrongful invasion. From the perspective of corrective justice, Ada then clearly has the primary responsibility to compensate Bob, but suppose she has fled the scene never to be seen again. Suppose further, as many are inclined to say, that Clare should disgorge her tainted $\$ 100$, at least when doing so would serve some important purpose. Should Clare give the money to Bob or David?

Source insensitive views hold that it is normatively irrelevant that Clare and Bob are causally connected in virtue of Ada's act. Clare might as well flip a coin, or give Bob and David \$50 each (Huseby 2015, p. 220). BPP, however, claims that Clare should give the money to Bob. One explanation for this draws on what the perpetrator of the injustice may have intended. Suppose Ada found Bob an annoying character that deserved to be taken down a peg and concluded that the best way of doing so would be to steal $\$ 100$ from him and give it to his least favorite person, Clare. Since the wrong now contains elements having to do with the particular distribution of losses and gains, it seems that Clare's causal connection to Bob's

\footnotetext{
12 To be precise, this is one of Cohen's (2016) two ways of specifying the subordination thesis, the other being that distributive justice is a necessary condition for corrective justice.

${ }^{13}$ As an anonymous referee points out, these matters are further complicated if we assume that the theft reversed a previous wrongful invasion, or indeed the unjust effects of an enacted policy. In this case, even if we assume that theft is generally a wrongful invasion, it is far from clear that the theft can be condemned from the perspective of corrective justice.
} 
loss does matter from the perspective of corrective justice. Clare has a reason to remedy specifically Bob's loss because this is necessary to defeat Ada's unjust plan. ${ }^{14}$

Tom Parr (2016) has recently defended a similar view. He argues that being the intended beneficiary of an injustice provides an extra reason to take remedial action. Goods that are the intended result of injustice are 'morally tainted', and moral taint generates 'an extra reason for the recipient to relinquish the good or the benefit it yields' (Parr 2016, p. 994). The fundamental reason for this, Parr argues, is that it is bad when immoral plans succeed, both because it is bad for the perpetrator and because it is impersonally bad. It follows that it is more important, for example, to remedy a loss that was deliberately inflicted on someone than remedying a comparable loss that resulted from natural causes.

This account seems broadly right to me. ${ }^{15}$ However, on one reading of Parr's view, he rejects source sensitivity. ${ }^{16}$ While he believes that intended beneficiaries of immoral plans have an extra reason to give up their tainted benefits, he thinks that it is unimportant whether the benefits go to the victims of the same plan as opposed to other people. The beneficiaries should consider 'the claims for compensation of victims of injustice more generally as well as those who have suffered the greatest harm' (Parr 2016, p. 995). In Thefts, for example, Clare should either flip a coin between giving $\$ 100$ to one of them or give them $\$ 50$ each.

Parr's position here follows from the aforementioned idea that it would be unfair to prioritize Bob over David given that they have undeservedly suffered comparable losses. This emphasis on distributive fairness is both natural and plausible given that Parr's ambition is to develop a more general normative framework for remedial duties. Here, however, we are interested specifically in corrective justice, and it seems clear that the idea of defeating immoral plans is perfectly able to supply BPP with a solution to the common-source problem from this perspective. This is because Ada's immoral plan would be more roundly defeated if Clare gave the money to Bob rather than David. After all, Ada's plan was to benefit Clare and to inflict a loss on Bob. Clare defeats the first part of the plan by disgorging the tainted $\$ 100$. But to defeat the second part of the plan it is necessary that she gives the money to Bob. If Clare were to give the money to someone else, Ada's plan to inflict a loss on Bob would succeed. This gives Clare a reason to return the money to Bob that she does not have in relation to other people. It is worth repeating that this does not mean that Clare should act on this reason when all relevant factors are taken into account. It only means that, as far as BPP is concerned, Clare has a special reason to give the money to Bob that she does not have towards other people.

Notice that it is crucial that Ada really has two plans - to benefit Clare and to inflict a loss on Bob-both of which are integral to what she aims to do. If Ada only wanted to benefit Clare, and Bob just happened to be the means to this end, perhaps even regrettably so from Ada's perspective, it is easier to see why Clare could flip a coin between Bob and David, or indeed give the money to someone else. For the purposes of defeating Ada's plan, it would not be necessary to give Bob $\$ 100$ unless her aim was to inflict a loss specifically on Bob. If Ada

\footnotetext{
${ }^{14}$ I think that the value of defeating immoral or unjust plans is the main normative force behind the example in Butt (2014, pp. 344-345).

${ }^{15}$ Parr's idea that immoral plans should be defeated for the wrongdoer's sake (as her life would otherwise be blighted) is more unusual and not necessary for the argument to go through. Parr also mentions that it is important to thwart immoral plans to discourage them (Parr 2016, p. 994).

${ }^{16}$ I write 'on one reading' since, as one anonymous referee points out, it is not clear what Parr would say about the cases I consider, which involve plans as to how harms and benefits are allocated. What I say in this paragraph and the next should therefore be read as a view that could be extrapolated from Parr's article.
} 
merely wanted to benefit Clare, Clare could defeat Ada's plan merely by giving up the unjust benefit she bestowed upon her. However, when Ada's plan was to benefit Clare and to inflict a loss on Bob, not returning the money to Bob would allow one of her aims to succeed.

The idea of defeating immoral plans can thus solve the common-source problem. It takes the idea of righting wrongs and then adds that the wrong may have been accompanied by an intention to benefit some people and harm others. Such an intention is of course not always there. But when it is, it seems plausible that beneficiaries of an injustice have a special reason to address the intended victims of the injustice.

\section{Restitution of Misallocated Benefits}

The previous discussion may appear unnecessarily complicated. A more immediate explanation for favoring Bob seems to be that Clare is in possession of Bob's money, not David's. This explanation takes us into the territory of restitution, which is a species of corrective justice that focuses on 'the objects that the victim has lost through the wrongdoing' and whose aim is to get those objects back 'into the hands of their rightful owner' (Goodin 2013, p. 481).

Drawing on restitution to solve the common-source problem is problematic for a number of reasons. However, I will argue that there is a sense of restitution-I will call it weak restitution - that BPP could adopt that would give the principle another way to solve this problem. But first it should be explained why restitution can be an uncomfortable fit for BPP.

\subsection{Problems with Restitution}

A first worry about drawing on restitution is that, in being an object-centered form of corrective justice, it pushes BPP in the direction of a resourcist as opposed to a welfarist understanding of the principle. On a welfarist understanding, 'to benefit from injustice' means 'to get more wellbeing as a result of injustice'. ${ }^{17}$ This is not necessarily the same as having someone else's resources as a result of injustice, which is what restitution focuses on. After all, it is possible that gaining the resources causes a loss in wellbeing. ${ }^{18}$

It is true that restitution pushes BPP in a resourcist direction. But there is nothing obviously wrong with that. Indeed, my impression is that BPP is mostly seen as a resourcist principle. Thus understood, getting (useful or valuable) resources as a result of injustice is the same thing as being a beneficiary of an injustice, at least on an actual-history understanding of the term. Needless to say, once unjust benefits are defined that way, the object-centeredness of restitution is not a problem.

A related critique is that restitution is only relevant for some kinds of resources. For example, the intuition that Clare has a reason to direct the benefit to Bob seems more secure

\footnotetext{
${ }^{17}$ If we understand BPP as a counterfactual view, it is not enough that Clare has been rendered better off than before; she must also be better off than otherwise. Such counterfactual claims inevitably raise difficult questions about the baseline against which the ex post situation is to be compared. These questions are equally pressing on a resourcist or welfarist understanding of 'better off', but resourcism is arguably easier to pair with an actualhistory understanding of BPP.

${ }^{18}$ For a good discussion of different 'currencies' of justice, see Hurley (2003, ch. 5). It is worth noting that it is typically good (bad) for one's welfare to receive (lose) resources, so it is unlikely that a resourcist and a welfarist understanding of BPP would have radically different implications.
} 
if what was stolen was a family heirloom rather than a fungible good like money. ${ }^{19}$ Moreover, restitution is entirely out of place when we consider non-material resources like education, since such resources cannot be taken from someone and be given to someone else. As Robert Goodin and Christian Barry (2014, p. 364) put it, restitution seems restricted to 'discrete, tangible "thing $[\mathrm{s}]$ ".' However, since there is no reason to say that BPP must be activated by every type of resource in the first place, it is unclear why this should be a problem.

The basic problem with appealing to restitution is instead that it appears to draw on a principle that is orthogonal to BPP: the principle that property should be returned to the rightful owner. One worry is that this renders BPP trivial and redundant, since the principle then only expresses an old idea with new terminology. The more serious worry, though, is that once we focus on restitution, it no longer seems to matter whether someone has come to possess someone else's property as a result of an unjust action (Parr 2016). To see this, suppose Bob's $\$ 100$ was not stolen but simply carried into Clare's possession by a gust of wind. From the perspective of restitution, this does not seem to make any difference for what Clare should do. She should return Bob's money all the same. This sits very uneasily with BPP since this principle states that there is something distinctive about benefiting from unjust actions.

Proponents of BPP have a choice between two options here. The first is to argue that injustice makes a difference in affecting the strength of the duty of restitution. The greater the wrong that was involved in depriving someone of his or her property, so this argument goes, the more pressing it is that the property be returned. Although I do not think that this idea is entirely hopeless, it is clearly somewhat unusual.

The second option is to argue that BPP is only supposed to operate in cases where property rights are not involved. The distinctive role of the principle is to explain why corrective justice still requires some kind of paying back, despite no property rights being violated. Bashshar Haydar and Gerhard Øverland (2014, p. 352) offer the following illustration:

Bribe. 'Adam and Sam are applying for the same job. It is certain that Adam will get the job since he is clearly the best candidate. Polly has a conflict with Adam and wants to make sure that he doesn't get the job. So he bribes the members of the selection committee to make sure that they will not offer the job to Adam. The plot works and Sam gets the job as a result. (Let us assume that it is no longer possible to reverse the decision and hire Adam, and that, had Sam failed to get the job, he would have obtained another job that pays $20 \%$ less.)'

Here the intuition is strong that Sam has a special reason to disgorge his extra income to Adam. But the basis for this, Haydar and Øverland argue, is not that Adam's property rights are violated. After all, while Sam has the job and income level Adam would otherwise have had, none of this is something Adam can claim ownership over. Haydar and Øverland suggest that the main factor explaining our reaction to Bribe is instead that Polly's wrongdoing was a direct interference in a 'structured competition'. Structured competitions occur when there is a

\footnotetext{
${ }^{19}$ Fungible goods are goods that are mutually substitutable. Money is fungible in the sense that one $\$ 100$ note is mutually substitutable with another $\$ 100$ note. It is admittedly possible that a particular $\$ 100$ note might have some special significance to me but the general point still stands.
} 
'relatively fair competitive procedure for allocating a given benefit and reward' (Haydar and Øverland 2014, p. 354). Polly's intervention ensured that the structured competition for the job misfired. $^{20}$

I agree that Sam is not in violation of Adam's property rights in the same way Clare is in violation of Bob's property rights in Thefts. Yet, it seems inaccurate to say that Sam's reason to direct his unjust benefit (the extra $20 \%$ income) to Adam is not one of restitution. After all, restitution is the idea of returning objects to their rightful owner, and although we cannot speak of Adam having property rights to the income of a job he never did, it is nevertheless plausible that the extra income morally belongs to him in the weaker sense that he would have had the extra income were it not for an injustice committed against him. To see this clearly, suppose Adam got the worse paid job Sam would have gotten had Polly not interfered. Surely it is then reasonable to say that the difference between Adam's (lower) income and Sam's (higher) income in some moral sense 'belongs' to Adam. This suggests that we should distinguish between a weaker and a stronger form of restitution. Strong restitution is when someone returns a discrete and individuated object (e.g., a car, a family heirloom) to the person who has property rights over that object. Weak restitution is when objects that are not discrete and individuated are returned to where they would have resided were it not for an unjust act. ${ }^{21}$ Sam giving his extra income to Adam is a case of weak restitution thus understood - he gives Adam the income that Adam would have gotten were it not for Polly's interference. ${ }^{22}$ The two types of restitution share the same concern that resources are not in the location they should be. They also agree that this misallocation should be reversed as a matter of corrective justice. But they differ as to which types of resource they deal with. Weak restitution applies to resources over which the rightful possessors have no property rights. It captures a looser, but still genuine, form of corrective justice.

\subsection{Weak Restitution for BPP}

The concept of weak restitution allows BPP to help itself to the forceful intuition that the distributive effects of unjust acts or policies should be reversed without making the principle into a mere extension of the idea that property should be returned to its rightful owners. For example, it is arguably weak restitution that is doing the work when people claim that consumers in rich countries have rectificatory obligations towards sweatshop workers in poor countries. The idea here is presumably that the consumers are enjoying cheap goods as a direct result of the fact that the workers are underpaid. This is tantamount to saying that the consumers have some wealth that, although not the workers' property, would have been enjoyed by the workers under fairer conditions. Weak restitution also seems involved when people argue that the costs of averting climate-related harm should be shouldered by those who have benefitted from greenhouse gas emissions. Past emissions have contributed significantly

\footnotetext{
${ }^{20}$ Notice that Bribe partially activates the aforementioned idea of defeating immoral plans, since Polly intended to prevent Adam from getting the job. Haydar and Øverland (2014) argue that an unjust intention can be a 'boosting' factor necessary to explain why the moral position of innocent beneficiaries is different compared to people in general. They also believe that it matters whether the perpetrator of the injustice directly bestowed the benefit upon the beneficiary.

${ }^{21}$ The structure of weak restitution is thus similar to the account sketched in Nozick (1974, pp. 152-153). See also Lawford-Smith (2014) on 'the world going other than it ought'.

${ }^{22}$ Some might prefer to call this 'compensation', but I here follow Goodin (2013) in saying that compensation is concerned with restoring victims' welfare whereas restitution is an 'object-centered' form of corrective justice.
} 
to the national wealth of the world's richest countries. Ed Page (2012) argues that the holders of that wealth are unjustly enriched and should therefore shoulder a large share of the burden of climate change mitigation and adaptation. A reasonable interpretation of this is that the rich countries are sitting on a wealth that would have been more evenly spread if the atmosphere's absorptive capacity had been more equitably used. Countries sitting on a disproportionate share of the tainted wealth therefore owe it to other countries to cover the costs of combatting climate change and its adverse effects (Page 2012, p. 315-316; cf. Duus-Otterström 2014). ${ }^{23}$

While weak restitution allows BPP to handle many familiar cases of benefiting from injustice, a worry is that it makes the principle apply in too many cases. Haydar and Øverland (2014, p. 351) think so, on the back of the following case:

Invasion. 'Country $A$ unjustifiably invaded country $B$ and destroyed its oil producing facilities. This has led to higher oil prices, which in turn benefitted country $C$, another oil producing country'.

Haydar and Øverland think that country $C$ has no special reason to assist country $B$ in this case. Their main reason for this is that the two countries are not engaged in a structured competition. They are not participating in a competitive procedure for a given benefit. Instead, they 'can be said to be competing only in the loose sense of being part of the same global oil market' (Haydar and Øverland 2014, p. 354). $C$ therefore owes $B$ no special assistance.

Weak restitution challenges that conclusion, since the important thing according to this perspective is that country $C$ is sitting on oil revenue that would have resided in country $B$ were it not for country A's unjust invasion. Contrary to Haydar and Øverland, however, I do not think that this is a counterintuitive implication. The fundamental concern behind weak restitution is that resources are allocated in a certain way because of an injustice, and this condition is satisfied in Bribe and Invasion alike. Indeed, from the perspective of corrective justice, it is not clear that the presence of a structured competition makes a crucial difference. What gives normative force to the idea of correcting interferences with competitions is that benefits are misallocated as a result of unjust acts, and benefits can clearly be misallocated in that sense even in the absence of structured competitions. The presence of a structured competition clarifies where a benefit would reside if no injustice were committed, but that is another matter. ${ }^{24}$ If the fundamental concern is correcting for misallocation of benefits, $C$ does have a special moral reason to disgorge its extra oil revenue and direct it specifically to $B$.

But the reason Haydar and Øverland resist applying BPP in Invasion might be that the benefiting looks too 'indirect'. If country $C$ benefits in the relevant sense from $A$ 's invasion, are we not forced to also say that, for example, oil workers in country $B$ who went on to find better jobs as a result of the invasion also benefit in the relevant sense? It is indeed crucial that BPP does not end up saying that every benefit that is causally downstream from an injustice comes within the purview of weak restitution. As Goodin and Barry argue (2014, p. 365) the benefit must be an 'essential' rather than an 'incidental' feature of the injustice. This is not the place to

\footnotetext{
${ }^{23}$ Climate change is a tricky case for BPP since it is not clear that extensive greenhouse gas emissions, for much of their history, could be called unjust, let alone be said to involve an intentionally immoral plan. See here Page's (2012) useful distinction between 'wrongful enrichment' and 'unjust enrichment' versions of BPP as well my account of 'objective' climate injustice (Duus-Otterström 2014). Intergenerationally, BPP also invites the nonidentity problem (Caney 2006). I cannot get further into these fascinating questions here.

${ }^{24}$ Structured competition clarifies where a benefit would reside because it specifies the actors involved and because there is a procedure for allocating the benefit. In a sports competition, for instance, we know that the gold medal belongs to the runner up if the original winner cheated.
} 
explore this important restriction on BPP, but let me just note that the restriction seems satisfied in a case like Invasion. Country $C$ 's increased revenue is a direct consequence of the ceasing oil export from country $B$, which (let us assume) would have exported oil at a normal rate were it not for the invasion. $C$ 's increased share of the oil market is an automatic result of $B$ 's decreased share.

Notice that the impression that $C$ owes $B$ some of its oil revenue is stronger if $A$ invaded $B$ in order to benefit $C$. This is because $C$ 's giving up some revenue to $B$ would then be necessary to defeat $A$ 's unjust plan. As this demonstrates, the ideas of weak restitution and defeating immoral plans are not competing but can complement each other.

\section{The Indirect Transfer Objection}

It may be objected that neither explanation solves the common-source problem because they are both vulnerable to what we may refer to as the indirect transfer objection. Consider again the case where Polly cheats Adam out of a well-paying job that Sam instead gets. Now consider:

- Direct Remedy. Sam gives $20 \%$ of his income to Adam.

- Indirect Remedy. Sam gives $20 \%$ of his income to a charity. Edna, who is unrelated to the whole situation, gives Adam a sum of money that is equivalent to $20 \%$ of Sam's income.

According to the indirect transfer objection, there is no difference between these two scenarios as far as corrective justice is concerned. In both scenarios, any plan Polly might have had to inflict a loss on Adam and to benefit Sam would be defeated, and weak restitution seems satisfied. This suggests that source sensitivity does not matter after all. Someone other than Sam can just as well right the wrong that was committed against Adam.

In response, recall that the common-source problem is not about explaining why Adam's loss must be remedied specifically by Sam. BPP should just happily accept that his loss could be adequately remedied in other ways. ${ }^{25}$ The problem instead consists of showing that Sam has moral reason to address Adam's loss that he does not have with people who have suffered losses in general. Thus, the challenge is not to differentiate between Direct Remedy and Indirect Remedy. It is to differentiate between the following scenarios:

- Source Sensitivity. Sam decides to give up $20 \%$ of his income. He gives it to Adam.

- Source Insensitivity. Sam decides to give up $20 \%$ of his income. He gives it to Donna, who has been cheated out of a similar job as Adam by someone else.

This is a challenge the two explanations discussed above can meet. In combination or taken separately, they explain why Sam has a reason of corrective justice to give the money to Adam

\footnotetext{
${ }^{25}$ One possibility is that the victim may be source sensitive: she will not consider herself fully compensated unless the beneficiary remedies her loss. At least as long as we subscribe to a subjective understanding of compensation according to which the victim's subjective welfare must be fully restored, this would speak in favor of the beneficiary remedying the victim. But it is not clear that this constitutes a principled reason for source sensitivity - if victims should not have this attitude, perhaps we would be justified in withholding full compensation. For instructive discussion of compensation, see Goodin (1989).
} 
that he does not have towards Donna. ${ }^{26}$ Of the two, it is fair to say that the one focusing on immoral plans is more robust. There is nothing arbitrary about Sam's differentiating between Adam and Donna when this is necessary to defeat Polly's immoral plan. But even weak restitution gives Sam a reason to direct his disgorged income to Adam. I readily admit, however, that weak restitution is more compelling when it comes to distinguishing between the following scenarios:

- Special Remedy. Adam is owed some extra income. The duty to provide the extra income falls on Sam.

- General Remedy. Adam is owed some extra income. The duty to provide the extra income falls on people in general.

Unlike Source Sensitivity and Source Insensitivity, these scenarios introduce different remedying agents, not victims. This is not the focus in this paper. I have been preoccupied with the more modest question of whether innocent beneficiaries of an injustice, if they are to disgorge their unjust benefits, have any reason to prioritize the victims of the injustice from which they benefit. But it is clear that BPP is relevant for these scenarios too-indeed, BPP is usually understood as a principle for selecting remedying agents - and weak restitution offers a reason to prefer Special Remedy to General Remedy, namely, that it is Sam who possesses the extra income that Adam would have enjoyed if it were not for Polly's interference.

The reader may still wonder about the strength of these reasons for source sensitivity. Do they mean that BPP should play a prominent role in the distribution of our final duties? The answer will differ depending on how much weight one attaches to corrective justice in the kind of cases I have considered. On one extreme, it could be argued that BPP provides a conclusive reason to direct one's unjust benefits to the victims, no matter how the victims fare in comparison to others. On the other extreme, it could be argued that BPP is nothing more than a tiebreaker, operative only when the victims and other potential recipients of the benefits are equal in all other respects. Although the former extreme is more implausible than the latter, neither position is particularly attractive, suggesting that the answer lies somewhere in the middle. My own view is that corrective justice is very important when it comes to what perpetrators of injustice should do, and somewhat important when it comes to what innocent beneficiaries of injustice should do, but that both are easily outweighed when basic needs or a decent minimum is at stake. But that is neither here nor there. My aim here has simply been to offer reasons for source sensitivity. It is another question whether these reasons carry much normative weight.

\section{Conclusion}

Many philosophers and political theorists nowadays believe that beneficiaries of an injustice may have special moral reason (or even a special duty) to remedy the harmful effects of that injustice even though they did not contribute to it. Several critics have suggested that it is normatively irrelevant that benefits and harms flow from the same unjust source. I have argued that innocent beneficiaries of an injustice may indeed have special moral reason to assist the

${ }^{26}$ For a similar formulation, focusing on singling out a remedying agent among many capable agents, see Haydar and Øverland (2014, p. 352). 
victims of the same injustice. Doing so might defeat the perpetrator's immoral plan and might be called for based on what I have called weak restitution. The Beneficiary Pays Principle is a relatively young normative principle that may well have many problems, but if I am right, the common-source problem is not one of them.

Acknowledgements Previous versions of the paper were presented at the University of Gothenburg, at the 2016 Nordic Network for Political Theory in Oslo, and at the Institute for Futures Studies and Ratio (both in Stockholm). I wish to thank everyone who attended those talks for valuable feedback. I owe a special debt of gratitude to Sune Lægaard and Tim Campbell for providing written comments on previous drafts, to Ed Page for extensive discussion, and to two anonymous referees of this journal. This research is part of the project 'Pollution-Sensitive Climate Justice: Sources, Thresholds, and Patterns', which is funded by the Swedish Research Council (grant number 2015-01346). I gratefully acknowledge their financial support.

Open Access This article is distributed under the terms of the Creative Commons Attribution 4.0 International License (http://creativecommons.org/licenses/by/4.0/), which permits unrestricted use, distribution, and reproduction in any medium, provided you give appropriate credit to the original author(s) and the source, provide a link to the Creative Commons license, and indicate if changes were made.

\section{References}

Anwander N (2005) Contributing and benefiting: two ground for duties to the victims of injustice. Ethics and International Affairs 19:39-45

Barry C, Kirby R (2017) Skepticism about beneficiary pays: a critique. J Appl Philos 34:285-300

Butt D (2007) On benefiting from injustice. Can J Philos 37:129-152

Butt D (2009) Rectifying International Injustice: Principles of Compensation and Restitution between Nations. Oxford University Press, Oxford

Butt D (2014) 'A doctrine altogether new and untenable': defending the beneficiary pays principle. J Appl Philos 31:336-348

Caney S (2005) Cosmopolitan justice, responsibility, and global climate change. Leiden Journal of International Law 18:747-775

Caney S (2006) Environmental degradation, reparations, and the moral significance of history. J Soc Philos 37 : $464-482$

Cohen A (2016) Corrective vs. distributive justice: the case of apologies. Ethical Theory Moral Pract 19:663-677

Duus-Otterström G (2014) The problem of past emissions and intergenerational debts. Crit Rev Int Soc Pol Phil $17: 448-469$

Duus-Otterström G (2017) Fairness-based retributivism reconsidered. Crim Law Philos 11:481-498

Goodin R (1989) Theories of compensation. Oxf J Leg Stud 9:56-75

Goodin R (2013) Disgorging the fruits of historical wrongdoing. Am Polit Sci Rev 107:478-491

Goodin R, Barry C (2014) Benefiting from the wrongdoing of others. J Appl Philos 31:363-376

Goodin R, Pasternak A (2016) Intending to benefit from wrongdoing. Polit Philos Econ 15:280-297

Gosseries A (2004) Historical emissions and free-riding. Ethical Perspectives 11:36-60

Haydar B, Øverland G (2014) The normative implications of benefiting from injustice. J Appl Philos 31:349-362

Hurley S (2003) Justice, Luck, and Knowledge. Harvard University Press, Cambridge

Huseby R (2015) Should the beneficiaries pay? Polit Philo Econ 14:209-225

Ivison D (2006) Historical injustice. In: Dryzek J, Honnig B, Phillips A (eds) The Oxford Handbook of Political Theory. Oxford University Press, Oxford, pp 507-525

Knight C (2013) Benefiting from injustice and brute luck. Soc Theory Pract 39:581-598

Lawford-Smith H (2014) Benefiting from failures to address climate change. J Appl Philos 31:392-404

Lippert-Rasmussen K (2017) Affirmative action, historical injustice, and the concept of beneficiaries. J Polit Philos 25:72-90

Miller D (2001) Distributing responsibilities. J Polit Philos 9:453-471

Nozick R (1974) Anarchy, State, and Utooia. Basic Books, New York

Page E (2012) Give it up for climate change: a defence of the beneficiary pays principle. International Theory 4 : $300-330$

Parr T (2016) The moral taintedness of benefiting from injustice. Ethical Theory Moral Pract 19:985-997

Pasternak A (2014) Voluntary benefits from wrongdoing. J Appl Philos 31:377-391 
Perry S (2000) On the relationship between corrective and distributive justice. In: Horder J (ed) Oxford Essays in Jurisprudence. Oxford University Press, Oxford, pp 237-263

Pogge T (2008) World Poverty and Human Rights, 2nd edn. Polity, Cambridge

Shue H (1999) Global environment and international inequality. Int Aff 75:531-545

Tadros V (2014) What might have been. In: Oberdiek J (ed) Philosophical Foundations of the Law of Torts. Oxford University Press, Oxford, pp 171-192

Thomson JJ (1973) Preferential hiring. Philos Public Aff 2:364-384 